\title{
Enhanced Photocatalytic Activity of ZnO Nanoparticles Co-Doped With Rare Earth Elements (Nd and Sm) Under UV Light Illumination
}

\section{P. Baskaran}

Bharathidasan Institute of Technology Campus, Anna University

\section{A. Pramothkumar}

Bharathidasan Institute of Technology Campus, Anna University

Mani P ( $\nabla$ drpmaut@gmail.com )

Bharathidasan Institute of Technology Campus, Anna University https://orcid.org/0000-0002-85970908

\section{Research Article}

Keywords: Nd/Sm co-doped ZnO NPs, Co-precipitation, Photocatalytic activity, Acid Orange 7 (AO-7), Acid Red 13 (AR-13)

Posted Date: November 1st, 2021

DOI: https://doi.org/10.21203/rs.3.rs-1026552/v1

License: (9) This work is licensed under a Creative Commons Attribution 4.0 International License. Read Full License 


\title{
Enhanced photocatalytic activity of ZnO Nanoparticles co-doped with rare earth elements (Nd and Sm) under UV light illumination
}

\author{
P. Baskaran, A. Pramothkumar, P. Mani* \\ Department of Physics, University College of Engineering, Bharathidasan Institute of \\ Technology Campus, Anna University, Tiruchirappalli-620 024, Tamil Nadu, India. \\ *Corresponding author Email: drpmaut@gmail.com
}

\begin{abstract}
In the present report, synthesis of pure, Nd-doped (1 wt.\%) and Nd/Sm (1 wt.\%) codoped Zinc Oxide ( $\mathrm{ZnO})$ Nanoparticles (NPs) by using simple co-precipitation method. PXRD pattern of all the synthesized samples exposes the hexagonal crystal structure of $\mathrm{ZnO}$ NPs without any impurity. The various functional groups presented in the synthesized samples were analyzed by FT-IR studies. From UV-Vis DRS spectra, the band gap was found to be $2.81 \mathrm{eV}$, 2.90 and $3.10 \mathrm{eV}$ respectively for pure, Nd-doped and Nd-Sm co-doped ZnO NPs. PL spectrum displays the broad emission at 393and $450 \mathrm{~nm}$ for all the synthesized samples. The agglomeration of flower-like morphology of pure ZnO NPs, flake-like structure of Nd-doped and rod-like morphology of $\mathrm{Nd} / \mathrm{Sm}$ co-doped $\mathrm{ZnO} \mathrm{NPs}$ were examined by SEM. Photocatalytic activity of the prepared samples for dye degradation of Acid Orange 7 (AO-7) and Acid Red 13 (AR-13) was studied under UV light. The result revealed that, the $\mathrm{Nd} / \mathrm{Sm}$ co-doped $\mathrm{ZnO} \mathrm{NPs}$ found to have efficient degradation candidate materials.
\end{abstract}

Keywords: Nd/Sm co-doped ZnO NPs; Co-precipitation; Photocatalytic activity; Acid Orange 7 (AO-7); Acid Red 13 (AR-13) 


\section{Introduction.}

$\mathrm{ZnO}$ NPs is a versatile n-type semiconducting material in the II-VI group elements with a direct band gap of $3.37 \mathrm{eV}$ and possess the most varied nanocrystalline designs. Also, it has high exciton energy $(60 \mathrm{meV})$, hexagonal wurtzite structure, low resistivity, good transparency, high electron mobility, non-toxicity, high photo stability and also has been used a countless remarkable applications like opto-electronics, solar cell, spintronics, sensors, gas sensors, antimicrobial, photoconductive, photocatalytic, PN junction diode liquid crystal display, magnetic storage media, lithium-ion battery and laser source [1-5]. Various synthesis method such as, combustion method, sol-gel method, hydrothermal method, polyol method, co-precipitation method, sonochemical method and simple soft chemical route were used to synthesis the ZnO NPs [6-7]. Among them methods, Co-precipitation method is the most convenient method for the synthesis of NPs due to its easiness in operation, low cost, no need of high temperature and simplicity when compared to other reported methods [8].

The clean environmental, safe drinking water and sufficient energy are highly polluted by several dyes coming out from the various factories like leather, textiles, printing, cosmetics, hair colouring, medical laboratories, convulsions mutagenic, plastics, foods, pharmaceuticals, teratogenic and other industries.In addition, most industrials dyes are easily soluble in water and which can cause severe disorders on aquatic organisms, humans and animals (affecting the brain, liver, skin, kidneys and nervous system) due to their high toxicity, low biodegradability, stability and mutability [9-10].In past few years, several techniques have been used for the removal of organic dye pollutants from the industrials waste water. among them, the photocatalysis methods is great treatment for the removal of organic dye pollutants from the industrial waste water due to low cost and environmentally friendly [11]. The 
various researchers are reported, the semiconducting nanostructured $\mathrm{ZnO}$ is a good effective material for photocatalyst activity due to low cost, excellent biocompatibility, high redox potential, outstanding chemical and physical durability, which is used for oxidative degradation of organic pollutants in wastewater [12-13]. In addition, the photocatalytic activity of $\mathrm{ZnO} \mathrm{NPs}$ is artificial by the fast recombination of charge carriers and comparatively lower charge separation, which decrease the efficiency of photocatalytic activity [9].Therefore, the photocatalytic activity of $\mathrm{ZnO}$ NPs can be easily improve the efficiency by doping or co-doping technique by using metals (Transition and Rare Earth metals).Also, efforts have been made by various material scientists to develop ZnO NPs with co-doped by rare earth metals such as $\mathrm{Eu}, \mathrm{Sm}, \mathrm{Gd}, \mathrm{Tb}, \mathrm{Er}$ and are significantly enhance the photocatalytic degradation of organic dye pollutants from the industrials waste water.In particular, rare earth metal doping with $\mathrm{ZnO}$ will have been bandgap energy is increases and the recombination of charge carrier is reducing which will increases of photocatalytic efficiency.The improvement of photocatalytic performance under visible light using Sm doped ZnO NPs was reported by Mohd Faraz et al., (2018) [14].N.K. Divya et al., (2017), also reported that the enhanced photocatalytic activity of Nd-doped $\mathrm{ZnO}$ NPs using methylene blue dye [15].The improved photocatalytic activity of Gd-Nd co-doped ZnO NRs was observed for methyl blue dye was reported by Javaid Akhtar et al., (2020) [16].The better photocatalytic activity of Er-Yb co-doped $\mathrm{ZnO}$ NPs was observed for the degradation of methyl orange dye was reported by Irshad Ahmadet al., (2019) [17].

Hence, the synthesis of pure $\mathrm{ZnO}(\mathrm{PZ}), \mathrm{Nd}$ doped $\mathrm{ZnO}(\mathrm{NZ})$ and $\mathrm{Nd}-\mathrm{Sm}$ co-doped $\mathrm{ZnO}$ NPs (NSZ NPs) using a co-precipitation and study of their photocatalytic activity for 
degradation of degradation of Acid Orange 7 and Acid Red 13 under UV light illimitation. Also, characterization such as structural and optical properties are also studied and reported.

\section{Experimental method}

\subsection{Materials}

Zinc nitrate dihydrate $\left[\mathrm{Zn}\left(\mathrm{NO}_{3}\right)_{3} \cdot 2 \mathrm{H}_{2} \mathrm{O}\right]$, samarium (III) nitrate hexahydrate [Sm $\left.\left(\mathrm{NO}_{3}\right)_{3} \bullet 6 \mathrm{H}_{2} \mathrm{O}\right]$, Neodymium (III) nitrate hexahydrate $\left[\mathrm{Nd}\left(\mathrm{NO}_{3}\right)_{3} \bullet 6 \mathrm{H}_{2} \mathrm{O}\right]$, sodium hydroxide $[\mathrm{NaOH}]$, Acid Orange 7 (AO-7) $\quad\left[\mathrm{C}_{16} \mathrm{H}_{11} \mathrm{~N}_{2} \mathrm{NaO}_{4} \mathrm{~S}\right], \quad$ Acid Red 13 (AR-13) $\left[\mathrm{C}_{20} \mathrm{H}_{11} \mathrm{~N}_{2} \mathrm{Na}_{2} \mathrm{O}_{7} \mathrm{~S}_{2}\right]$, ethanol $\left[\mathrm{C}_{2} \mathrm{H}_{5} \mathrm{OH}\right]$, Acetone $\left[\left(\mathrm{CH}_{3}\right)_{2} \mathrm{CO}\right]$ and Double Distilled (DD) water. All the chemical elements were bought from Merck India Ltd. (99\% purity).

\subsection{Synthesis of $\mathrm{ZnO}$ NPs}

$0.5 \mathrm{M}$ of $\mathrm{Zn}\left(\mathrm{NO}_{3}\right)_{3} \cdot 2 \mathrm{H}_{2} \mathrm{O}$ was liquified into DD water $(50 \mathrm{ml})$ under magnetic stirrer at room temperature for 10 mins. After that, $\mathrm{NaOH}$ solution was added drop by drop into $\mathrm{Zn}$ $\left(\mathrm{NO}_{3}\right)_{3} \cdot 2 \mathrm{H}_{2} \mathrm{O}$ solution until the $\mathrm{pH}$ attains 12 and the mixture was stirred continuously $(2 \mathrm{hrs}$.). The solution transformed to black precipitates. The precipitate was filtered and washed three times using ethanol and DD water. The collected precipitate was dried at $80^{\circ} \mathrm{C}$ (hot oven). Finally, it was annealed at $250^{\circ} \mathrm{C}$ for 2 hours. The final product was labeled as PZ NPs.

\subsection{Synthesis of Nd doped ZnO NPs}

$\mathrm{Zn}\left(\mathrm{NO}_{3}\right)_{3} \cdot 2 \mathrm{H}_{2} \mathrm{O}(0.5 \mathrm{M})$ was liquified into DD water $(50 \mathrm{ml})$ under magnetic stirrer. Then, 1 wt. $\%$ of Neodymium nitrate $\left[\mathrm{Nd}\left(\mathrm{NO}_{3}\right)_{3} \cdot 6 \mathrm{H}_{2} \mathrm{O}\right]$ from the total weight was added into $\mathrm{Zn}\left(\mathrm{NO}_{3}\right)_{3} \cdot 2 \mathrm{H}_{2} \mathrm{O}$ solution. The remaining process was the same, as for the synthesis of pure ZnO NPs and the obtained NPs was labeled as NZ NPs. 


\subsection{Synthesis of Nd/Sm co-doped ZnO NPs}

To synthesis $\mathrm{Nd} / \mathrm{Sm}$ co-doped $\mathrm{ZnO} \mathrm{NPs}, \mathrm{Zn}\left(\mathrm{NO}_{3}\right)_{3} \cdot 2 \mathrm{H}_{2} \mathrm{O}(0.5 \mathrm{M})$ was taken and liquified in $50 \mathrm{ml}$ of DD water under magnetic stirrer. After that, $1 \mathrm{wt} . \%$ of Neodymium nitrate $[\mathrm{Nd}$ $\left.\left(\mathrm{NO}_{3}\right)_{3} \bullet 6 \mathrm{H}_{2} \mathrm{O}\right]$ and samarium (III) nitrate hexahydrate $\left[\mathrm{Sm}\left(\mathrm{NO}_{3}\right)_{3} \bullet 6 \mathrm{H}_{2} \mathrm{O}\right]$ was mixed with the $\mathrm{Zn}\left(\mathrm{NO}_{3}\right)_{3} \cdot 2 \mathrm{H}_{2} \mathrm{O}$ solution. The above-mentioned synthesis method of pure $\mathrm{ZnO}$ NPs worked the same way, to complete the process of the synthesis of $\mathrm{Nd} / \mathrm{Sm}$ co-doped $\mathrm{ZnO}$ NPs. Then the sample was labeled as NSZ NPs.

\subsection{Photocatalytic experiment.}

Two separate dyes, namely Acid Orange 7 (AO-7) and Acid Red 13 (AR-13), were used for the photocatalytic study. Two dyes were evaluated individually from $100 \mathrm{ml}$ of 20 $\mathrm{mg} / \mathrm{L}$ concentrations and $0.1 \mathrm{mg}$ of the photocatalyst was been used as a catalyst dose. With the commercial configuration of the photo-reactor, the process is accomplished. The module comprising of a 150W tungsten halogen lamp for the source of light with emission wavelengths ranging around 340 to $850 \mathrm{~nm}$ was installed between the borosilicate well with double-wall having outlet and inlet wherein the cooling liquid was circulating to optimize the temperature. The solution of $2 \mathrm{M}$ sodium nitrate $\left(\mathrm{NaNO}_{2}\right)$ was used here as cooling liquid to screen the UV light produced from the light source $(320-430 \mathrm{~nm})$. The aliquots of the reaction mixture were collected at regular intervals (20 minutes) and characterized by a UV-Vis spectrophotometer in order to analyze the dye molecules disintegration. Using the following equation further calculates the percentage of degradation of the dye molecules with regard to time.

$$
\eta=\left(1-\frac{c}{c_{0}}\right) \times 100(\%)
$$


Where $c_{0}$ is the preliminary dye solution intensity before illumination and $c$ is the dye solution intensity after illumination with light at time (t).

\section{Results and discussion}

\subsection{Structural properties}

Fig. 1 shows the PXRD patterns of (a) PZ, (b) NZ and (c) NSZNPs recorded by using X' pert pro-PAN analytic X-ray diffractometer. The peaks positioned at $31.73^{\circ}, 34.34^{\circ}, 36.20^{\circ}$ $, 47.46^{\circ}, 56.52^{\circ}, 62.75^{\circ}, 66.29^{\circ}, 67.85^{\circ}$ and $68.99^{\circ}$ corresponds to the miller planes of (100), (002), (101), (102), (110), (103), (200), (112), (201) are in good agreement with the hexagonal crystal structure of ZnO NPs (JCPDS card No. 01-080-0074). The PXRD patterns reveal that there are no secondary peaks associated to $\mathrm{Nd}$ or Sm or any other impurity. Which indicated the $\mathrm{Nd}^{3+}$ and $\mathrm{Sm}^{3+}$ ions have been incorporated into $\mathrm{Zn}^{2+}$ ions in the $\mathrm{ZnO}$ lattice. From the Fig. 2, the high peak intensity of (101) plane of NZ and NSZ NPs decreases and shifted towards lower angle side when compared with PZ NPs due to the interaction of larger ionic radius of $\mathrm{Nd}^{3+}(0.99 \AA)$ and $\mathrm{Sm}^{3+}(1.08 \AA)$ with smaller ionic radii of $\mathrm{Zn}^{2+}(0.74 \AA)$ [18-19]. Debye Scherrer's formula can be used to estimate the average crystallite size of samples.

$$
D=\frac{K \lambda}{\beta \cos \theta}
$$

Where, $\mathrm{K}, \lambda, \theta, \beta$ represent the shape factor $(0.9), \mathrm{X}$-ray wavelength $(0.1541 \mathrm{~nm})$, diffraction angle and full width half maximum respectively. The average crystallite size measured is found to be increased as $16.23 \mathrm{~nm}$ for PZ NPs, 23.10nm for NZ NPs and 25.84 
$\mathrm{nm}$ for NSZ NPs respectively. As a result, the increase in average crystalline size for the PZ and NZ NPs was observed due to the addition of dopants $\mathrm{Nd}$ and Nd/Sm.

The vibrational properties of synthesis samples were investigated using FT-IR Tracer 100 Shimadzu spectrophotometer (vibrational scale range of $4000-400 \mathrm{~cm}^{-1}$ ). FT-IR spectra of (a) PZ, (b) NZ and (c) NSZNPs are shown in Fig. 3. The absorption peak that emerges at $3426 \mathrm{~cm}^{-1}$ and $1613 \mathrm{~cm}^{-1}$ are attributed to the $\mathrm{H}-\mathrm{O}-\mathrm{H}$ stretching and $\mathrm{O}-\mathrm{H}$ bending vibration due to surface adsorbed $\mathrm{H}_{2} \mathrm{O}$ groups during the studies [20]. The peaks located at $1452 \mathrm{~cm}^{-1}$ and $867 \mathrm{~cm}^{-1}$ reveal the $\mathrm{C}-\mathrm{H}$ stretching vibration, which arises from alcohol used in synthesis [21]. The peak at $1051 \mathrm{~cm}^{-1}$ and $712 \mathrm{~cm}^{-1}$ are ascribed due to stretching vibrations of C-O via $\mathrm{CO}_{2}$ absorbed in the air medium [22]. $\mathrm{Zn}-\mathrm{O}$ vibrational mode is confirmed from the observed peak positioned at $561 \mathrm{~cm}^{-1}$ [22]. As a result, the peak of ZnO NPs is suppressed by adding co-dopant of $\mathrm{Nd}^{3+}$ and $\mathrm{Sm}^{3+}$ ions, which confirms it is successfully doped into the $\mathrm{Zn}-\mathrm{O}$ lattice.

\subsection{Optical properties}

Optical properties of synthesized materials were explored by Hitachi UV3010-Visible Diffuse Reflectance Spectroscopy (UV - DRS). Fig. 4exposes the UV-DRS Reflectance spectra of(a) PZ, (b) NZ and (c)NSZ NPs in the wavelength ranges from 200 to $1200 \mathrm{~nm}$. The absorption band cut-off at $440 \mathrm{~nm}$ for PZ NPS was shifted to $425 \mathrm{~nm}$ for NZ NPs and $390 \mathrm{~nm}$ for NSZ NPs. From the fig, blue shift is observed for NZ and NSZ NPs when compared to PZ NPs. Optical bandgap energy ( $\mathrm{E}_{\mathrm{g}}$ ) of (a) PZ, (b) NZ and (c) NSZNPs respectively calculated from Tauc's relation.

$$
[(R) h v / t]^{1 / 2}=A\left(h v-E_{g}\right)
$$


Where $\alpha, h v, A, n, E_{g}, R$ and $F(R)$ are referred to absorption coefficient, photon energy, proportionality constant, the optical bandgap, reflectance of spectrum Kubelka-Munk relation $\left(F(R)=(1-R)^{2} / 2 R\right)$, respectively. The $E_{g}$ is observed from Tauc's plot drawn between $h v$ and $[F(R) h v]^{2}$. The calculated $\mathrm{E}_{\mathrm{g}}$ values are $2.81,2.90$ and $3.10 \mathrm{eV}$ for $\mathrm{PZ}$, NZ and NSZNPs respectively. The $\mathrm{E}_{\mathrm{g}}$ of NZ and NSZ NPs increases when compared with PZ NPs due to the presence of quantum confinement effect and oxygen stoichiometry [23-24]. According to UV reports of the synthesized samples, the NSZNPs harvested high photon energy during the light illumination and it is responsible for enhanced photocatalytic activity.

Photoluminescence (PL) spectra of synthesized samples was investigated by florescence spectrometer (Hitachi F-4500) at room temperature. The PL spectra of (a) PZ, (b) NZ (c) NSZ NPs (excitation wavelength $=320 \mathrm{~nm}$ ) are shown in fig..6. From the results, the two emission peaks Near Band Edge (NBE) emission (393 nm) and blue emission (450 $\mathrm{nm}$ )are attributed to the photo-induced electron- hole recombination of free excitons on the surface of ZnO NPs [25-26]. When compared with PZ NPs, the PL emission intensity of NZ and NSZ NPs decreases with respect to addition of dopants $\left(\mathrm{Nd}^{3+}\right.$ and $\mathrm{Sm}^{3+}$ ions) into $\mathrm{ZnO}$ NPs due to various defects such as interstitial oxygen, zinc and oxygen vacancy [27]. The results confirm that the synthesized material possesses potential capability to promote photocatalytic activity.

\subsection{Morphological properties}

The surface morphology of the synthesized samples was investigated by Scanning Electron Microscope (SEM-ZEISS EV018) with Energy Dispersive X-ray spectrum (EDX).

SEM images of (a \& b) PZ, (c \& d) NZ and (e \& f) NSZNPs at the resolution of $1 \mu \mathrm{m}$ and 
200nm (Fig. 7). Fig. 7 (a \& c) reveals the agglomeration of flower-like morphology of PZ NPs, 7 (c \& d) shows the agglomerated flake-like morphology of NZ NPs and 7 (e \& f) presents the perfectly oriented rod-like morphology of NSZ NPs. From the results, the morphology of the prepared material is improved while doping. The coexistence of $\mathrm{Nd}^{3+}$ and $\mathrm{Sm}^{3+}$ ions in the $\mathrm{ZnO}$ lattice might be the reason for the improved the morphology of the synthesized NPs.Fig.8 shows the EDAX spectra of (a) PZ, (b) NZ NPs and (c) NSZ NPs. From the Figure 8(a), PZ NPs has O/Zn weight ratio of 44.51/55.49, NZ NPs (Figure8(b)) has $\mathrm{O} / \mathrm{Zn} / \mathrm{Nd}$ weight ratio of 43.62/55.45/0.93 and NSZ NPs (Figure 7(c)) has $\mathrm{O} / \mathrm{Zn} / \mathrm{Nd} / \mathrm{Sm}$ weight ratio of $47.52 / 50.72 / 0.85 / 0.91$. The existence of $\mathrm{Zn}, \mathrm{O}, \mathrm{Nd}$ and $\mathrm{Sm}$ atoms in the produced nanomaterials is proven from the spectra.

\subsection{Photocatalytic activity}

The photocatalytic reaction encompassing the heterogeneous nano photocatalyst generally takes place underneath the fundamental aspect that the incident photon with equal energy to that of the material's bandgap energy is consumed by the valence band (VB) electrons of that substances when light hits the semiconductor materials and excited to the conductive band (CB). Consequently, in the photocatalyst substance, electron-hole isolation is formed. Such CB electrons are then interfered in the dye solution with reactive oxygen species and generate superoxide anions $\left(\mathrm{O}_{2}^{-}\right) \cdot \mathrm{H}_{2} \mathrm{O}$ in the reaction mixture interact with the holes in the VB, which then it produces $(\cdot \mathrm{OH})$ radicals. Such formed superoxide anions $\left(\mathrm{O}_{2}{ }^{-}\right)$ and $(\cdot \mathrm{OH})$ radicals then interact with molecules and mineralize the dye from toxic to nontoxic. The advanced oxidation processes (AOP's) are commonly referred to such set chemical reactions as mentioned above. 
The descriptions of photocatalytic experimental setup are already mentioned in this manuscript in section-2 (experimental method). Two distinct organic textile dyes, such as Acid Orange 7 (AO-7) and Acid Red 13 (AR-13), were taken in proper proportions in separate beakers to analyze the photocatalytic ability of the synthesized nanoparticles. From all the three synthesized materials, $0.1 \mathrm{mg}$ of catalyst was taken and combined individually with the dye solutions. To maintain absorption/desorption stability between the dye solution and the catalyst, the dye solutions with catalyst dosage are gently stirred to blend well enough and held in the dark for 1 hour. Afterwards, to activate a photocatalytic process, the dye solutions are moved to the photo-reactor framework. The lamp was continually illuminated, and to ensure optimum interaction between the nano-catalyst and dye molecules, the catalyst loaded dye solution was mixed softly and steadily. To evaluate the breakdown of the dye molecules, the aliquots of the dye solutions are taken and analyzed with a UVspectrophotometer. In Fig.9 (a-c) and Fig.10 (a-c) accordingly, the decomposition UV spectrum of PZ, NZ and NSZ NPs loaded AO-7 and AR-13 dyes has been shown. The absorption maximum intensity peaks obtained for AO-7 and AR -13 at $486 \mathrm{~nm}$ and $550 \mathrm{~nm}$, respectively, from the spectrum and are reduced considerably as the reaction time increases. Hence, these factors prove the decay of dye molecules along with time. For each interval of time, the $\mathrm{C} / \mathrm{C}_{0}$ was computed and a plot was sketched between successive $\mathrm{C} / \mathrm{C}_{0}$ values to corresponding reaction time periods for all synthesized materials PZ, NZ and NSZ NPs to evaluate the proportion of the dye molecules destruction and is being illustrated in Fig. 11 (A \& B) for AO 7 and AR 13 dyes, respectively. The obtained degradation efficiency (\%) verses reaction time (T) is shown in Fig. 12. (a \& b). The performance of degradation PZ, NZ and NSZ NPs is measured as $52 \%, 75 \%, 82 \%$ for AO-7 dye and $50 \%, 67 \%, 80 \%$ for AR- 13 
dye around 120 minutes. The maximum destruction of AO-7and AR-13 dye respectively reaches $82 \%$ and $80 \%$ with UV radiation by NSZ photocatalyst at 120 minutes. According to the materials, the degradation effectiveness extends from PZ to NZ to NSZ NPs. From the results, the photon induced recombination of charge carrier is suppressed by addition of $\mathrm{Nd}^{3+}$ and $\mathrm{Sm}^{3+}$ ions into $\mathrm{ZnO}$ NPs, resulting in NSZ degradation efficiency increase.

\subsubsection{Reaction mechanism for the degradation process:}

$$
\begin{aligned}
& \text { [ZnO (or)Nd: } \mathrm{ZnO} \text { (or) } \mathrm{Nd} / \mathrm{Sm}: \mathrm{ZnO}]+\mathrm{h} v \rightarrow \mathrm{h}^{+}(\mathrm{VB})+\mathrm{e}^{-}(\mathrm{CB}) \\
& \mathrm{Nd}^{3+}+\mathrm{e}^{-} \longrightarrow \mathrm{Nd}^{2+} \\
& \mathrm{Sm}^{3+}+\mathrm{e}^{-} \rightarrow \mathrm{Sm}^{2+} \\
& \mathrm{Nd}^{2+}+\mathrm{O}_{2} \rightarrow \mathrm{O}_{2}^{\bullet-}+\mathrm{Nd}^{3+} \\
& \mathrm{Sm}^{2+}+\mathrm{O}_{2} \longrightarrow \mathrm{O}_{2}^{\cdot-}+\mathrm{Sm}^{3+} \\
& \mathrm{O}_{2}+\mathrm{e}^{-} \rightarrow \mathrm{O}_{2}^{\cdot-} \\
& \mathrm{e}^{-}+\mathrm{O}_{2} \longrightarrow \mathrm{OH}^{-}+\mathrm{OH}^{\bullet} \\
& \mathrm{O}_{2}{ }^{\bullet-}+\mathrm{H}_{2} \mathrm{O} \longrightarrow \mathrm{HO}_{2}{ }^{\bullet}+\mathrm{OH}^{\bullet} \\
& 2 \mathrm{HO}_{2}{ }^{\bullet} \rightarrow \mathrm{H}_{2} \mathrm{O}_{2}+\mathrm{O}_{2}{ }^{\bullet} \\
& \mathrm{e}^{-}+\mathrm{H}_{2} \mathrm{O}_{2} \rightarrow \mathrm{OH}^{-}+\mathrm{OH}^{\bullet} \\
& \mathrm{h}^{+}+\mathrm{OH}^{-} \rightarrow \mathrm{OH}^{\bullet} \\
& \mathrm{h}^{+}+\mathrm{H}_{2} \mathrm{O} \longrightarrow \mathrm{H}^{+}+\mathrm{OH}^{\bullet}
\end{aligned}
$$$$
\mathrm{OH}^{\bullet}+\mathrm{AO}-7 \& \mathrm{AR}-13 \rightarrow \mathrm{CO}_{2}+\text { Mineralized products }+\mathrm{H}_{2} \mathrm{O}
$$ 


$$
\mathrm{O}_{2}{ }^{\cdot-}+\mathrm{AO}-7 \text { \& AR-13 } \rightarrow \mathrm{CO}_{2}+\text { Mineralized products }+\mathrm{H}_{2} \mathrm{O}
$$

It is verified that the reaction mechanism follows the pseudo first-order kinetics for the degradation phenomenon and the reaction rate for the degradation process was determined through the Langmuir-Hinshelwood relationship. A plot between $\ln \left(\mathrm{C} / \mathrm{C}_{0}\right)$ with their corresponding reaction period is displayed in Fig.13 (A \& B) for AO 7 and AR 13 dyes separately.

$$
\ln \left(\frac{c}{c_{0}}\right)=k t
$$

It was concluded from all of the above results obtained that the decomposition percentage was enhanced by providing $\mathrm{Sm}^{3+}$ element into the nanostructures of $\mathrm{ZnO}$. Further the $1 \mathrm{wt} \%$ of $\mathrm{Nd} / \mathrm{Sm}$ co-doped $\mathrm{ZnO} \mathrm{NPs}$ for both AO-7 and AR-13 dyes received the maximum percentage of deterioration. With the addition in the $\mathrm{Nd}^{3+}$ and $\mathrm{Sm}^{3+}$ ions into the $\mathrm{ZnO}$ crystal lattice the optical properties of the material is altered heavily. The optical absorption range of the material is blue shifted which is directly proportional to the $\mathrm{Nd}^{3+}$ $/ \mathrm{Sm}^{3+}$ concentrations, and this is confirmed from the DRS spectrum. Hence, this increase in the optical band gap value will help the photo-generated electrons to stay in the conduction band for a while and thus the photocatalytic behaviour of the material is enhanced. Also, the impurity $\mathrm{Sm}$ and $\mathrm{Nd}$ atoms will create the intermediate energy levels in the material, so that the photo-excited electrons will be trapped at these sub energy levels and thus it reduces the electron-hole recombination rate which is confirmed by PL spectrum. This phenomenon is also one of the reasons for the enhancement in photocatalytic activity of the synthesized materials. The degradation mechanism is schematically represented in Fig.14. The calculated 
photocatalytic parameters for all the produced materials were comparatively listed in the Table 1.

\section{Conclusion}

Pure (PZ), Nd doped ZnO (NZ)and Nd/Sm co-doped ZnO (NSZ)NPs (1 wt. \%) were synthesized by using a simple co-precipitation process. The hexagonal crystal structure of all synthesized samples without any impurities was confirmed by PXRD pattern. From the FTIR studies, the various functional groups are present in the synthesized samples was identified. From the DRS spectra, the energy band gap increase from $2.81 \mathrm{eV}$ to $3.10 \mathrm{eV}$ were observed by the addition of dopants $(\mathrm{Nd} / \mathrm{Sm})$ due to their quantum confinement effect. The decrease in intensity at near band edge and blue emission was observed in PL spectrum due to the addition of dopant $\mathrm{Nd}$ and $\mathrm{Nd} / \mathrm{Sm}$ as co-dopant with $\mathrm{ZnO} \mathrm{NPs}$. From SEM images, the addition of dopants has modified the surface morphology of PZ NPs. Also, the prepared NPs were used as a photocatalyst under UV light illumination to degrade the AO-7 and AR-13 synthetic dyes. The NSZ NPS has shown higher degradation efficiency as compared to PZ and NZ NPs. Under UV light illumination, the NSZ NPs achieved $82 \%$ and $82 \%$ degradation of AO-7 and AR-13 dye respectively after 120 minutes of irradiation. Also, the apparent rate constant and reaction kinetics are investigated. Since, the NSZ NPs is highly bio-compatible and inexpensive, it may be a good option for photocatalytic dye degradation purposes. 


\section{Reference}

1. J. H. Zheng, J. L. Song, Z. Zhao, Q. Jiang, and J. S. Lian, Optical and magnetic properties of Nd-doped ZnO nanoparticles, Cryst. Res. Technol. 1, 1-6 (2012)

2. A. T. Ravichandran, R. Karthick, A. Robert Xavier, R. Chandramohan, Srinivas Mantha, Influence of $\mathrm{Sm}$ doped $\mathrm{ZnO}$ nanoparticles with enhanced photoluminescence and antibacterial efficiency, J Mater Sci: Mater Electron. 28, 6643-6648 (2017).

3. J.-Q. Wen, J.-M. Zhang, G.-X. Chen, H. Wu, X. Yang, the structural, electronic and optical properties of $\mathrm{Nd}$ doped $\mathrm{ZnO}$ using first-principles calculations, Phys. E: LowDimens. Syst. Nanostructures. doi: 10.1016/j.physe.2018.01.002.

4. I. Loyola Poul Raj, S. Valanarasu, K. Hariprasad, Joice Sophia Ponraj, N. Chidhambaram, V. Ganesh, H. Elhosiny Ali, Yasmin Khairy, Enhancement of optoelectronic parameters of $\mathrm{Nd}$-doped $\mathrm{ZnO}$ nanowires for photodetector applications, Opt. Mater. 109, 110396 (2020).

5. H E Okur, N Bulut, T Ates and O Kaygili, Structural and optical characterization of Smdoped ZnO nanoparticles. Bull. Mater. Sci. 42, 199 (2019)

6. Rosari Saleh, Nadia Febiana Djaja, UV light photocatalytic degradation of organic dyes with Fe-doped ZnO nanoparticles, Superlattice Microstruct. 74, 217-233 (2014)

7. K. Rekha, M. Nirmala, Manjula G. Nair, A. Anukaliani, Structural, optical, photocatalytic and antibacterial activity of zinc oxide and manganese doped zinc oxide nanoparticles, Phys B: condens. matter. 405 3180-3185 (2010) 
8. Belkhaoui C, Mzabi N, Smaoui H, Investigations on structural, optical and dielectric properties of Mn doped ZnO NPs synthesized by co-precipitation method, Mater. Res. Bullet. https://doi.org/10.1016/j.materresbull.2018.11.006.

9. Tauseef Munawar, Sadaf Yasmeen, Fayyaz Hussain, Khalid Mahmood, Altaf Hussain, M. Asghar, Faisal Iqbal, Synthesis of novel heterostructure $\mathrm{ZnO}-\mathrm{CdO}-\mathrm{CuO}$ nanocomposite: Characterization and enhanced sunlight driven photocatalytic activity, Mater. Chem. Phys. 249, 122983 (2020)

10. T. Sumithra, C. Lydia Pearline, M. John Abel, A. Pramothkumar, P Fermi Hilbert Inbaraj and J. Joseph Prince, Studies on structural and optical behavior of $\mathrm{SnO}_{2} / \mathrm{CuMn}_{2} \mathrm{O}_{4}$ nanocomposite developed via two-step approach for photocatalytic activity Mater. Res. Exp. 6, 115047 (2019)

11. M. R. Hoffmann, S. T. Martin, W. Choi, and D. W. Bahnemann, Environmental applications of semiconductor photocatalysis, Chem. Rev. 95, 69-96 (1995)

12. Kahsay, M. H., Tadesse, A., Rama Devi, D., Belachew, N., \& Basavaiah, K. Green synthesis of zinc oxide nanostructures and investigation of their photocatalytic and bactericidal applications. RSC Adv. 9(63), 36967-36981 (2019)

13. Shafi, A., Ahmad, N., Sultana, S., Sabir, S., \& Khan, M. Z. Ag2S-Sensitized NiO-ZnO Heterostructures with Enhanced Visible Light Photocatalytic Activity and Acetone Sensing Property. ACS omega, 4(7), 12905-12918 (2019)

14. Mohd Faraz, Faria K. Naqvi, Mohammad Shakir and Neeraj Khare, Synthesis of samarium-doped zinc oxide nanoparticles with improved photocatalytic performance and recyclability under visible light irradiation, New J. Chem. DOI: 10.1039/c7nj03927a. 
15. N. K. Divya, P. P. Pradyumnan, Enhancement of photocatalytic activity in Nd doped $\mathrm{ZnO}$ with an increase in dielectric constant, J Mater Sci: Mater Electron. 28, 2147-2156 (2017)

16. Javaid Akhtar, M.B. Tahir, M. Sagir, Hisham Saeed Bamufle, Improved photocatalytic performance of $\mathrm{Gd}$ and $\mathrm{Nd}$ co-doped $\mathrm{ZnO}$ nanorods for the degradation of methylene blue, Cerams. Int.46, 11955-11961 (2020)

17. Irshad Ahmad, Inexpensive and quick photocatalytic activity of rare earth (Er, $\mathrm{Yb})$ codoped $\mathrm{ZnO}$ nanoparticles for degradation of methyl orange dye, Sep. Purif. Technol. 227, 115726 (2019)

18. Sunil Chauhan, Manoj Kumar, Sandeep Chhoker, S. C. Katyal, V. P. S. Awana, Structural, vibrational, optical and magnetic properties of sol-gel derived $\mathrm{Nd}$ doped $\mathrm{ZnO}$ nanoparticles, J Mater Sci: Mater Electron. 24, 5102-5110 (2013)

19. Deepawali Arora, K. Asokan, Aman Mahajan, Harjeet Kaur and D. P. Singh, Structural, optical and magnetic properties of $\mathrm{Sm}$ doped $\mathrm{ZnO}$ at dilute concentrations, RSC Adv., 6 , 78122 (2016)

20. Noei, H., Qiu, H., Wang, Y., Löffler, E., Wöll, C., \& Muhler, M., The identification of hydroxyl groups on $\mathrm{ZnO}$ nanoparticles by infrared spectroscopy. Phys. Chem. Chem. Phys. 10, 7092-7097 (2008).

21. A. Albert Manoharan, R. Chandramohan, R. David prabu, S. Valanarasu, V. Ganesh, M. Shkir, A. Kathalingam, S. AlFaify, Facile synthesis and characterization of undoped, Mn doped and $\mathrm{Nd}$ co-doped $\mathrm{CuO}$ nanoparticles for optoelectronic and magnetic applications, J. Mol. Struct. doi: 10.1016/j.molstruc.2018.06.018. 
22. Odireleng Martin Ntwaeaborwa, Sefako J. Mofokeng, Vinod Kumar, Robin E. Kroon, Structural, optical and photoluminescence properties of $\mathrm{Eu}^{3+}$ doped $\mathrm{ZnO}$ nanoparticles, Spectrochem. Acta A: Mol. Biomol. 182 (2017) 42-49.

23. Etacheri, V., Roshan, R., Kumar, V., Mg-doped $\mathrm{ZnO}$ nanoparticles for efficient sunlightdriven photocatalysis. ACS appl. mater. interf. 4 2717-2725 (2012)

24. Aggarwal, N., Kaur, K., Vasishth, A., Verma, N. K., Structural, optical and magnetic properties of Gadolinium-doped $\mathrm{ZnO}$ nanoparticles. J. Mater. Sci. Mater. Electron. 27, 13006-13011 (2016).

25. Shinde, K. P., Pawar, R. C., Sinha, B. B., Kim, H. S., Oh, S. S., \& Chung, K. C. (2014). Study of effect of planetary ball milling on $\mathrm{ZnO}$ nano powder synthesized by coprecipitation. J. alloys compd. 617, 404-407 (2013)

26. K. C. Verma, Navdeep Goyal and R. K. Kotnala Lattice defect-formulated ferromagnetism and UV photo-response in pure and $\mathrm{Nd}$, Sm substituted $\mathrm{ZnO}$ thin films, Phys. Chem. Chem. Phys., 21, 12540 (2019)

27. N. Mohamed Basith, J. Judith Vijaya, L. John Kennedy, M. Bououdina, Structural, optical and room-temperature ferromagnetic properties of $\mathrm{Fe}$-doped $\mathrm{CuO}$ nanostructures, Physica E 53, 193-199 (2013) 


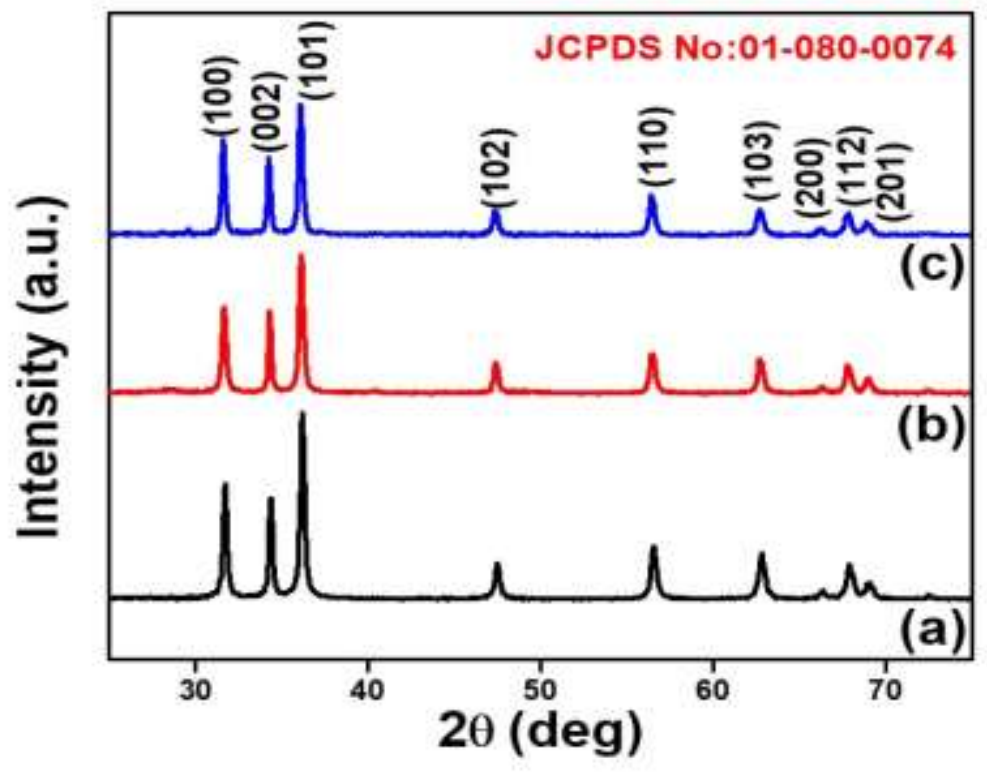

Fig. 1. PXRD patterns of (a) PZ, (b) GZ and (c) GSZ NPs.

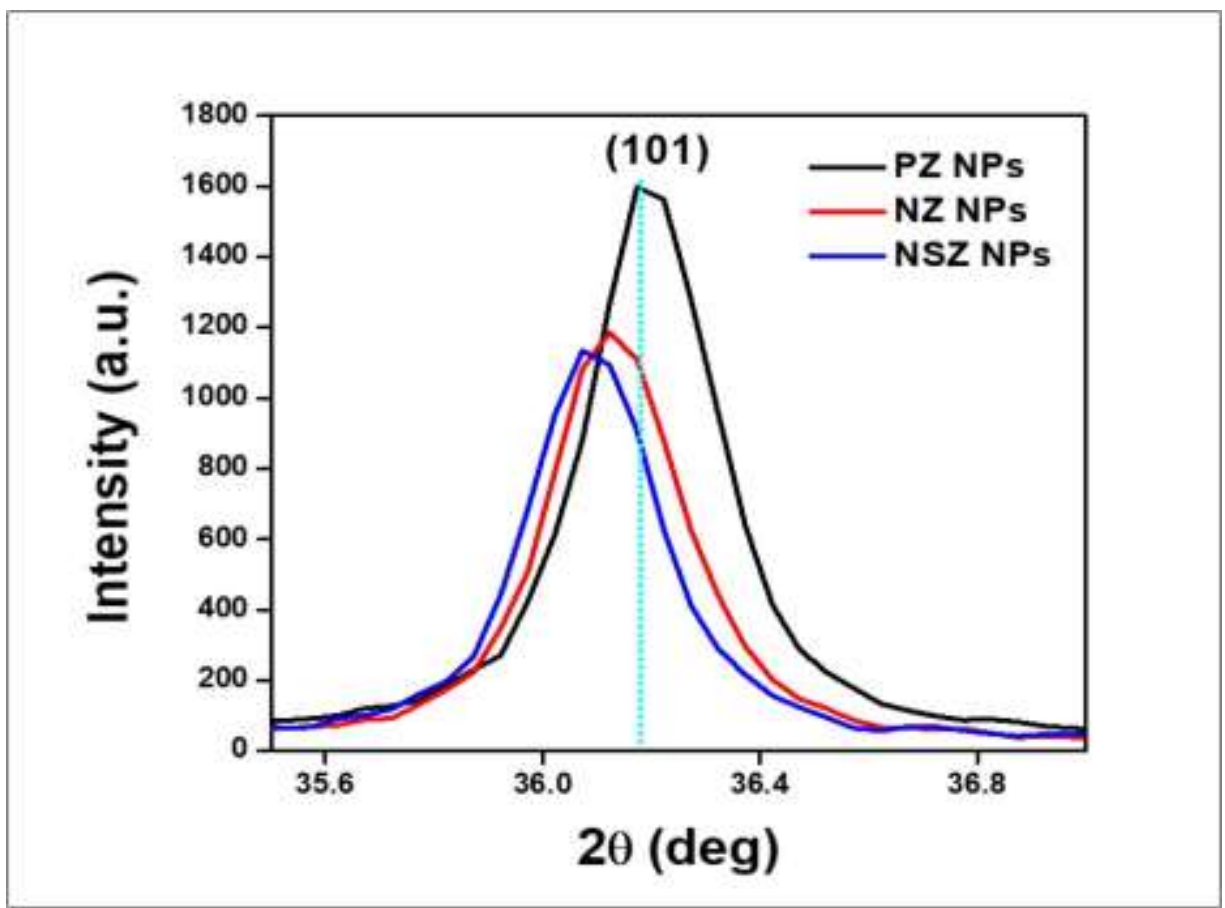


Fig. 2. Magnified PXRD pattern of Synthesized samples.

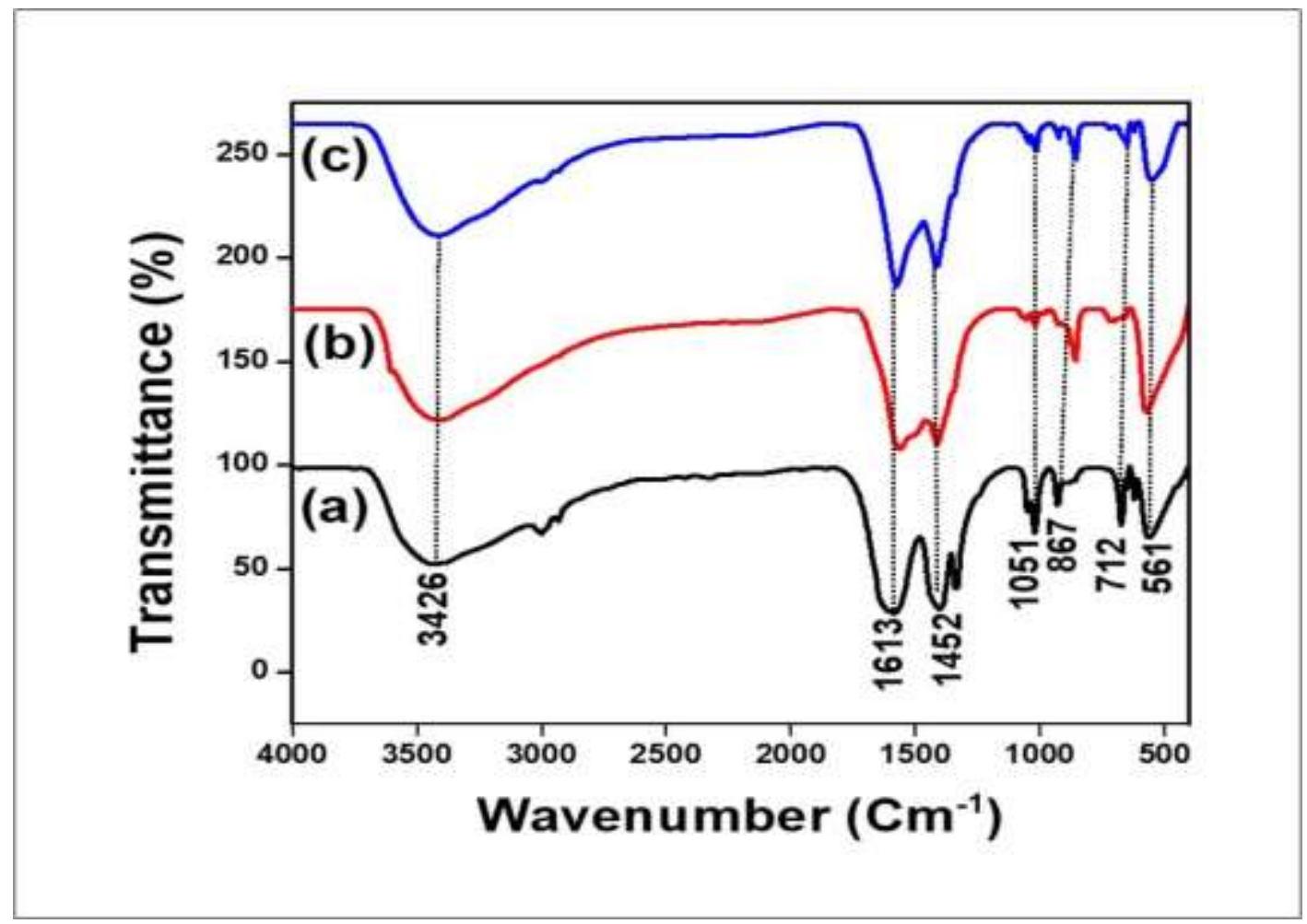

Fig. 3. FT-IR spectra of (a) PZ, (b) NZ and (c) NSZ NPs. 


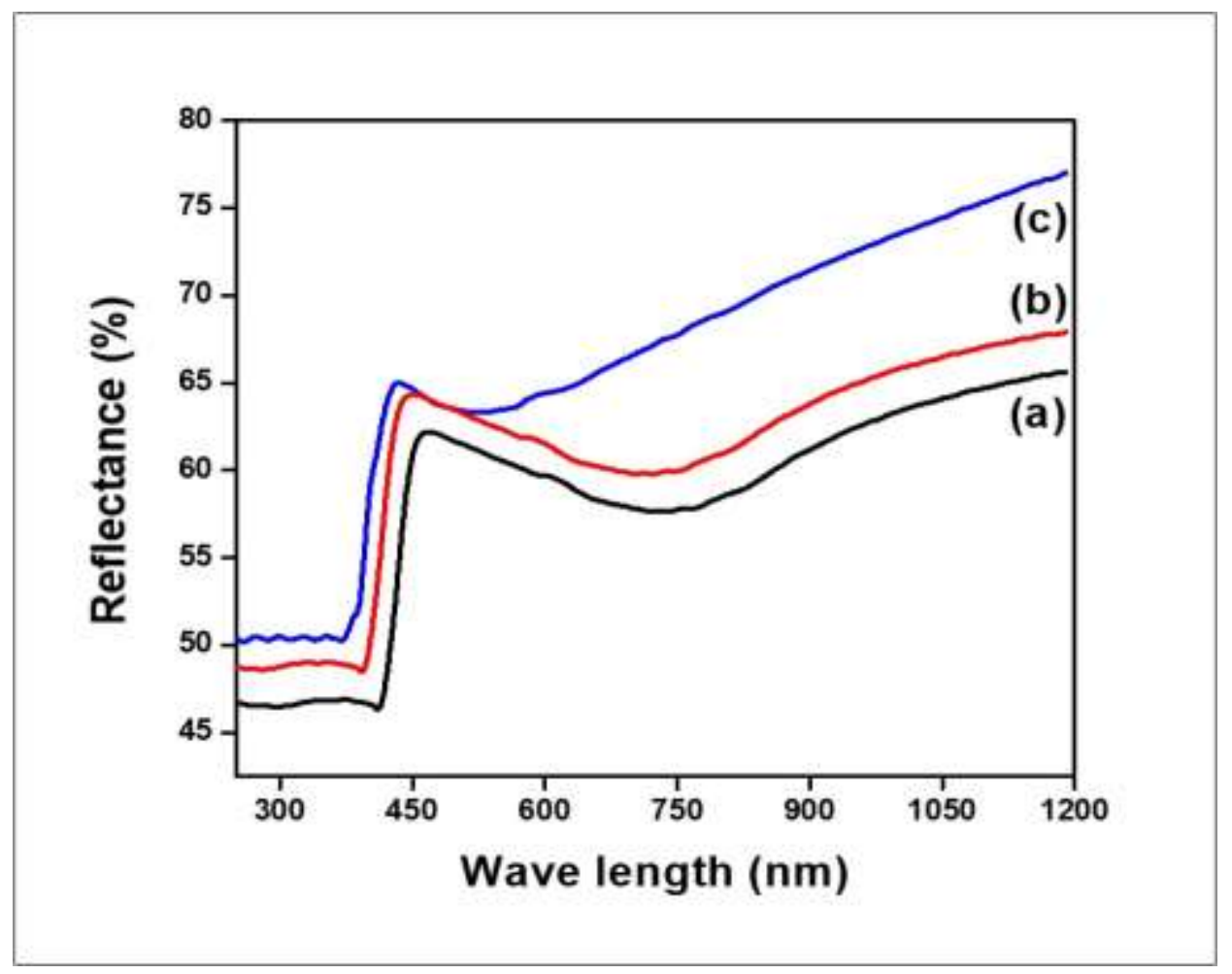

Fig.4. UV-DRS Reflectance (\%) spectra of (a) PZ, (b) NZ and (c) NSZ NPs.

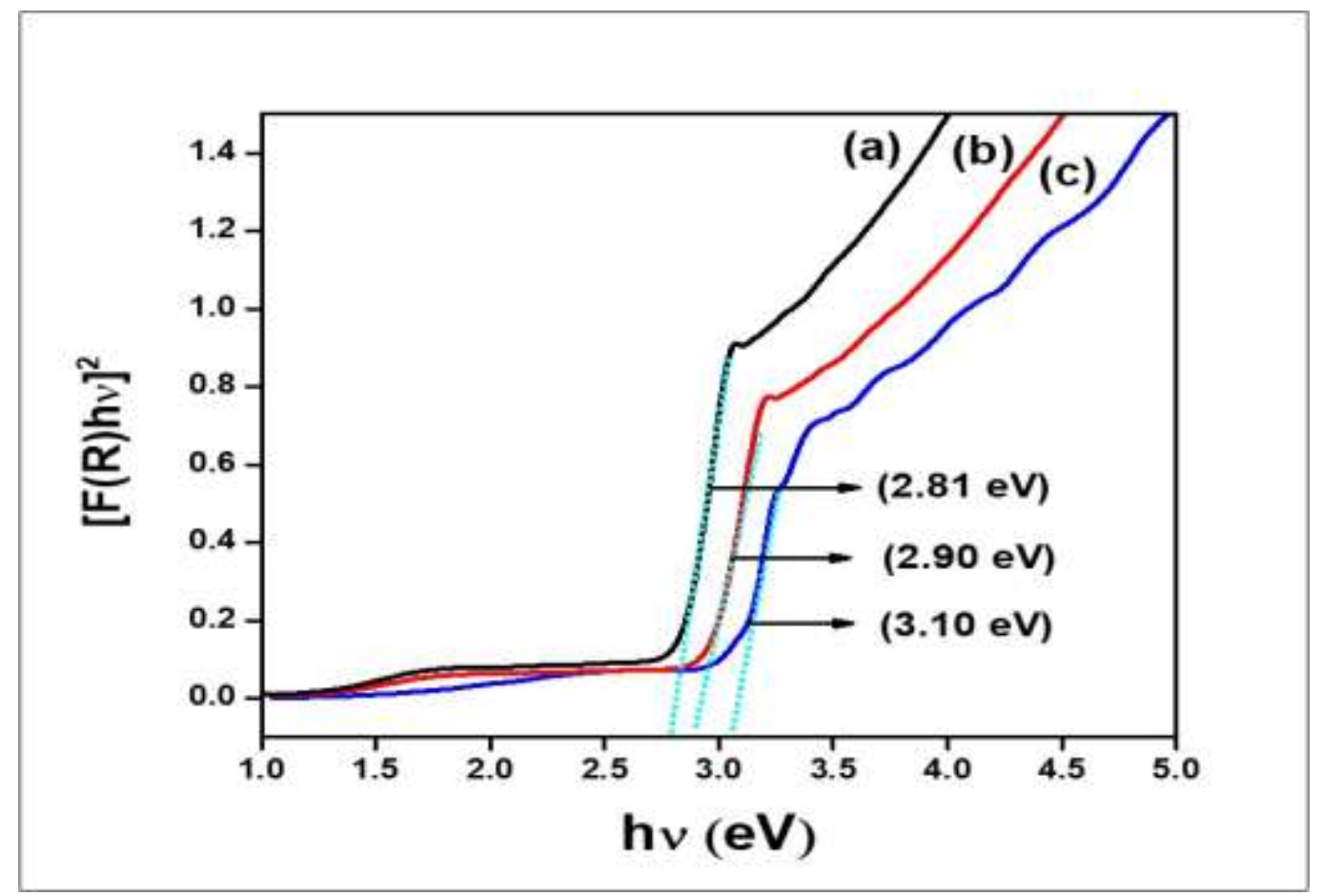

Fig. 5. Tauc's plot of (a) PZ, (b) NZ and (c) NSZ NPs. 


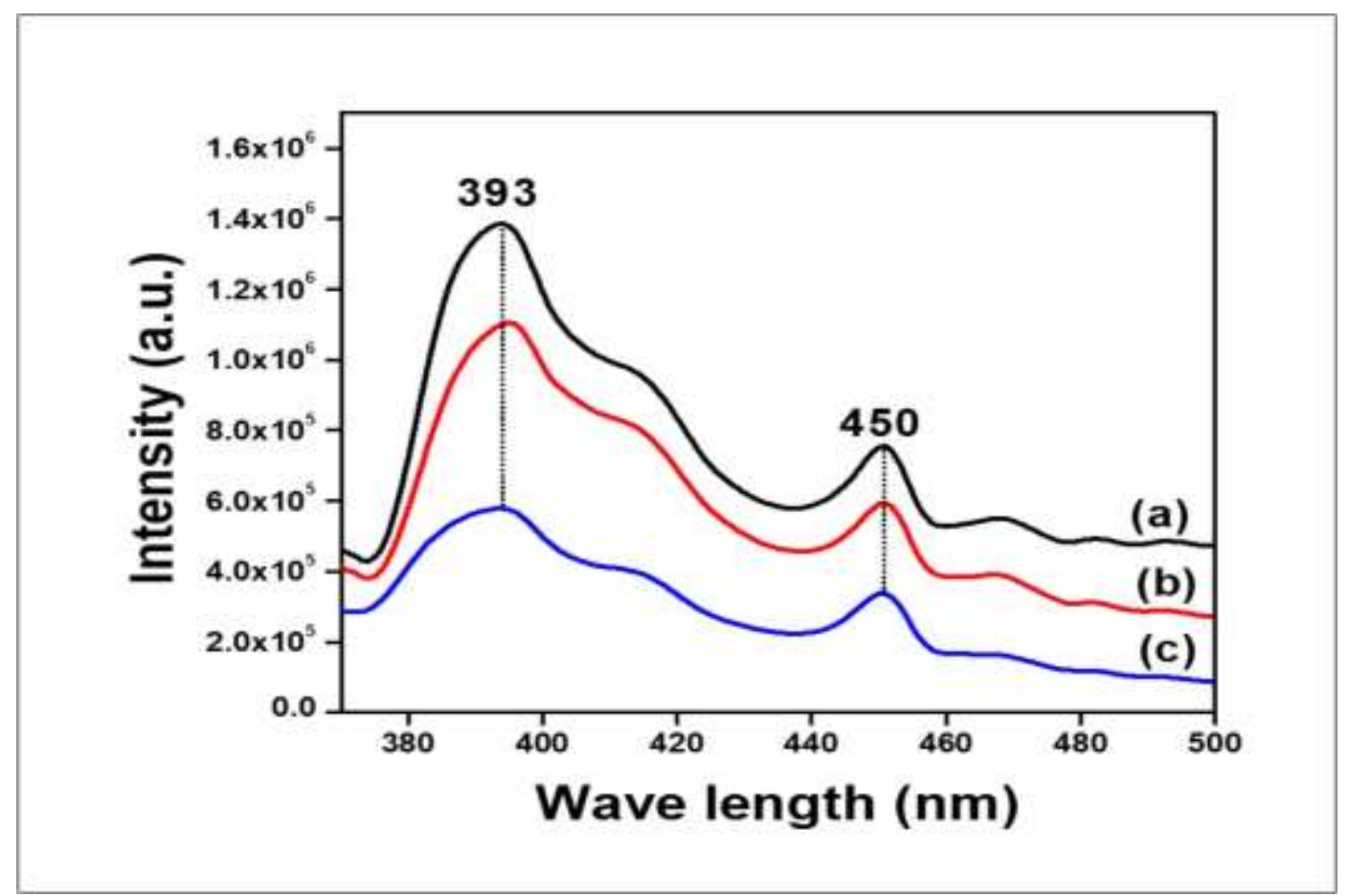

Fig.6. PL spectra of (a) PZ, (b) NZ and (c) NSZ NPs. 


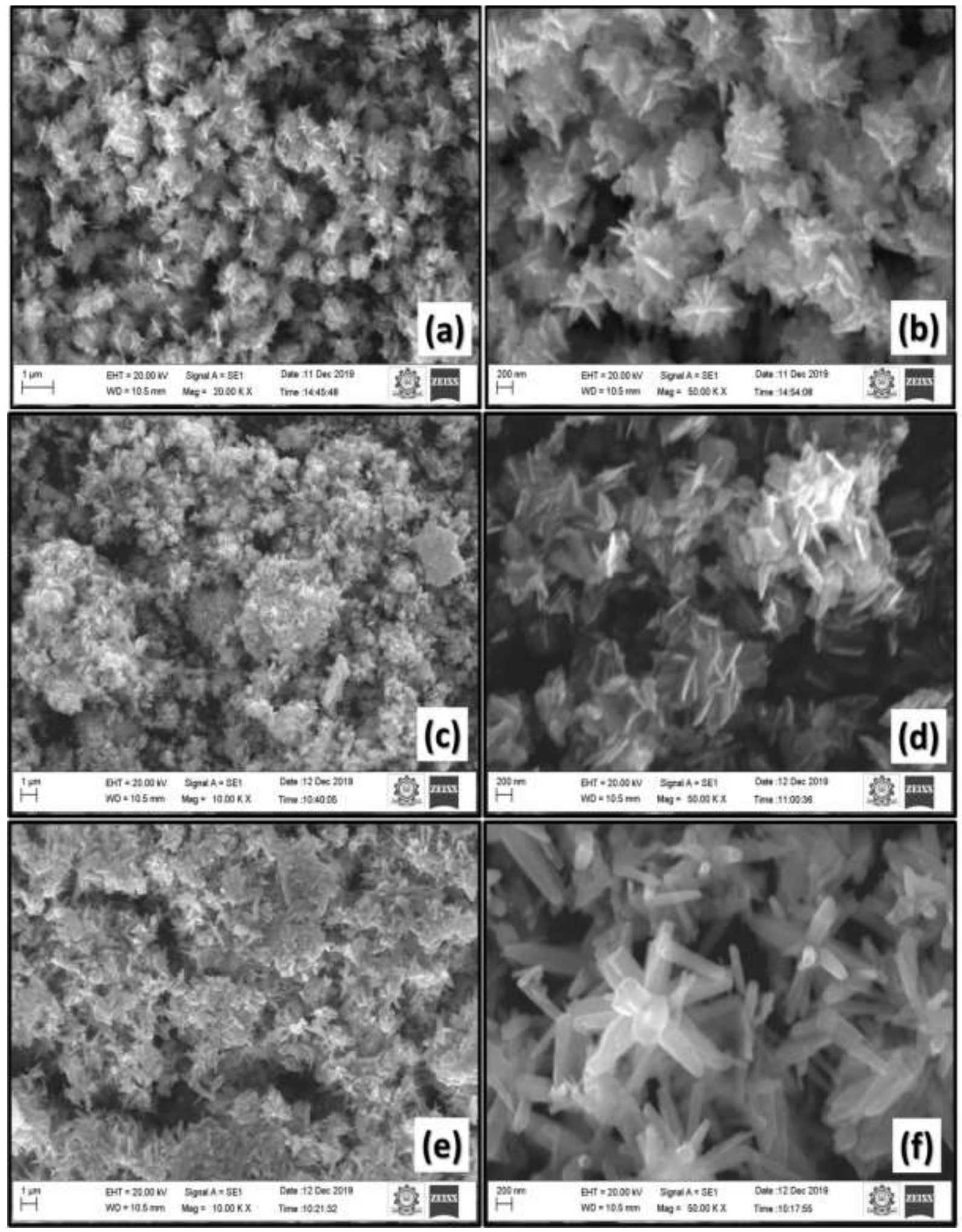

Fig.7.SEM images of (a \& b) PZ, (c \& d) NZ and (e \& f) NSZ NPs. 

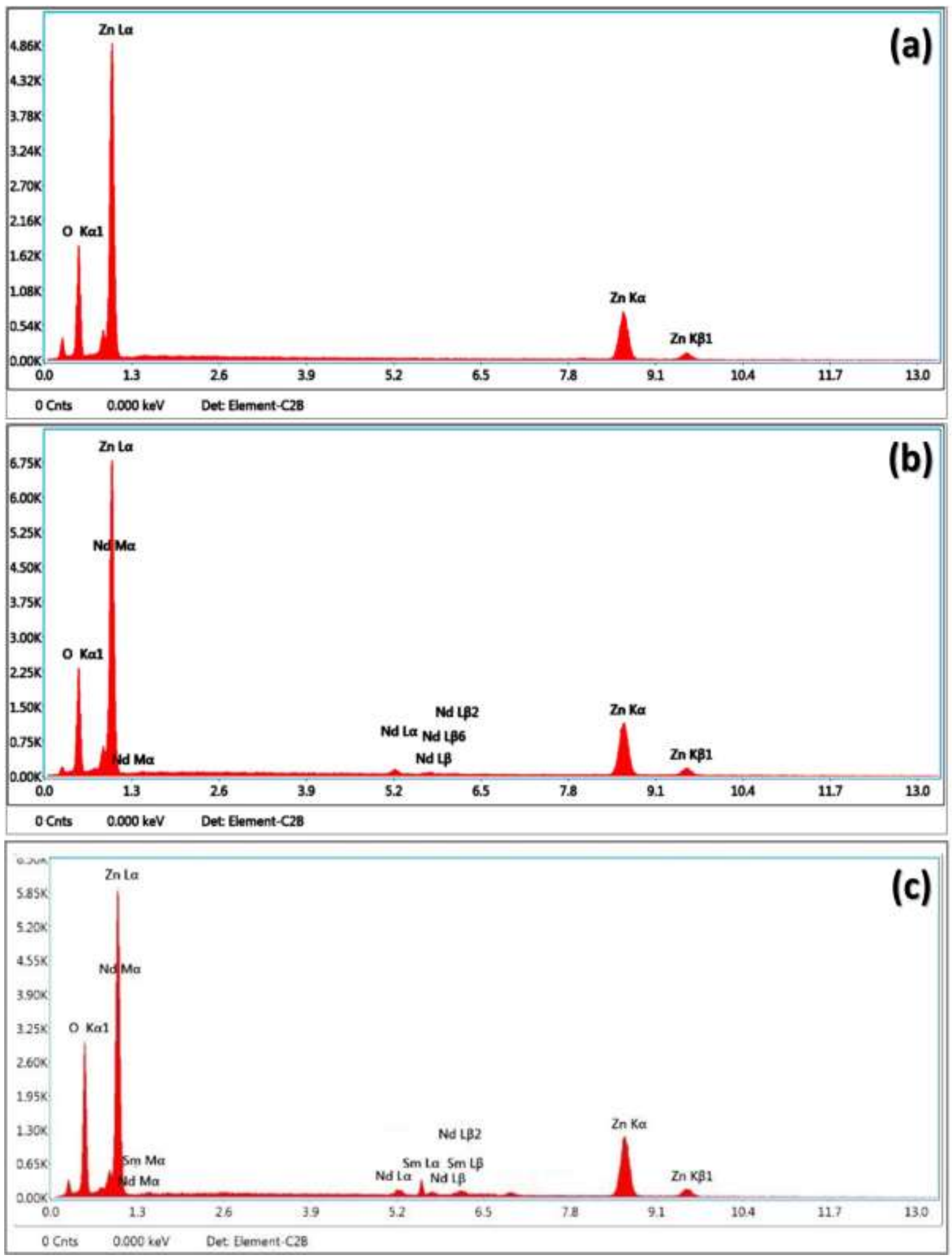

Fig. 8. EDAX spectra (a) PZ, (b) NZ and (c) NSZ NPs. 


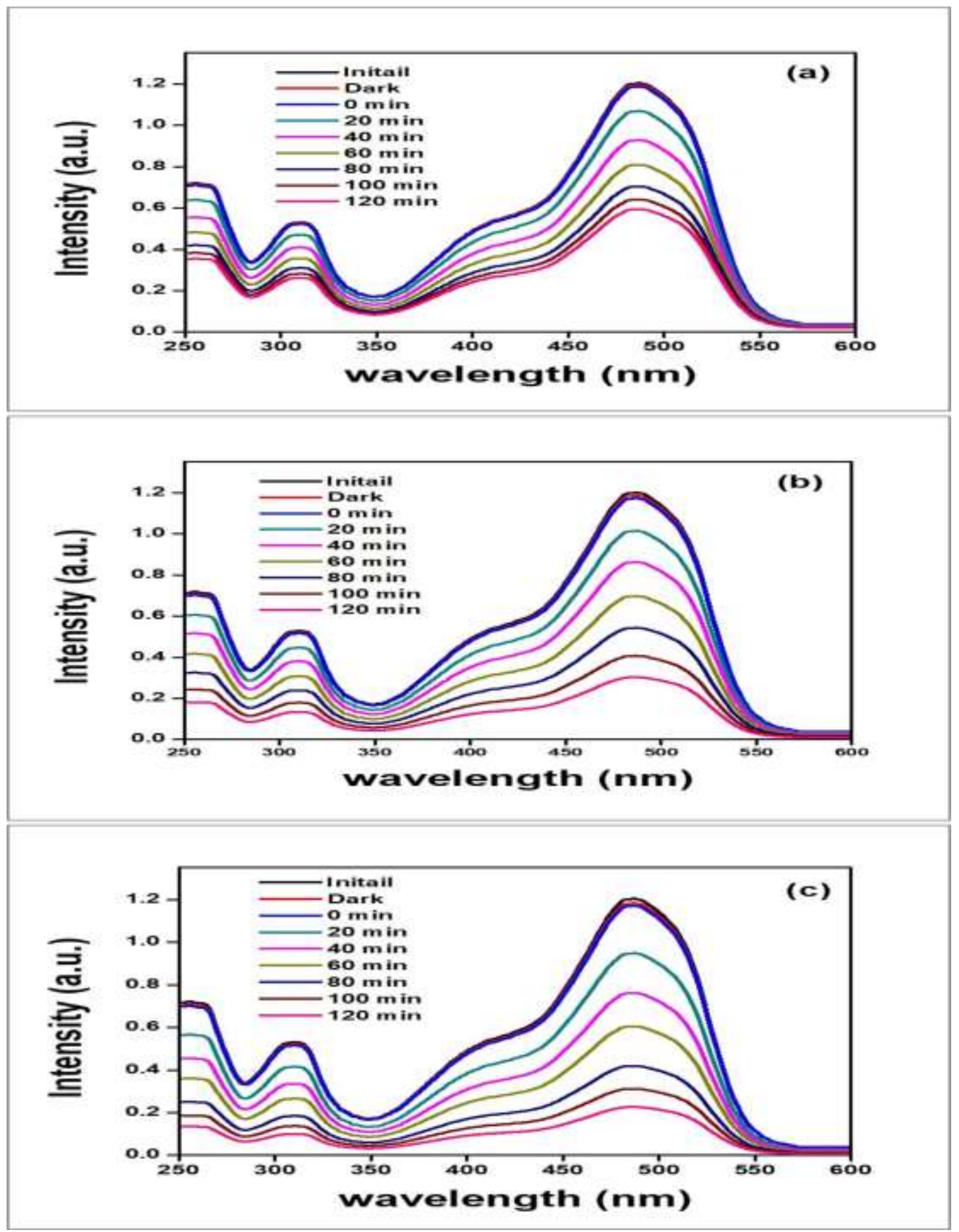

Fig. 9. Time dependent UV absorbance spectra of AO-7 dye with (a) PZ, (b) NZ, (c) NSZ photocatalysts. 


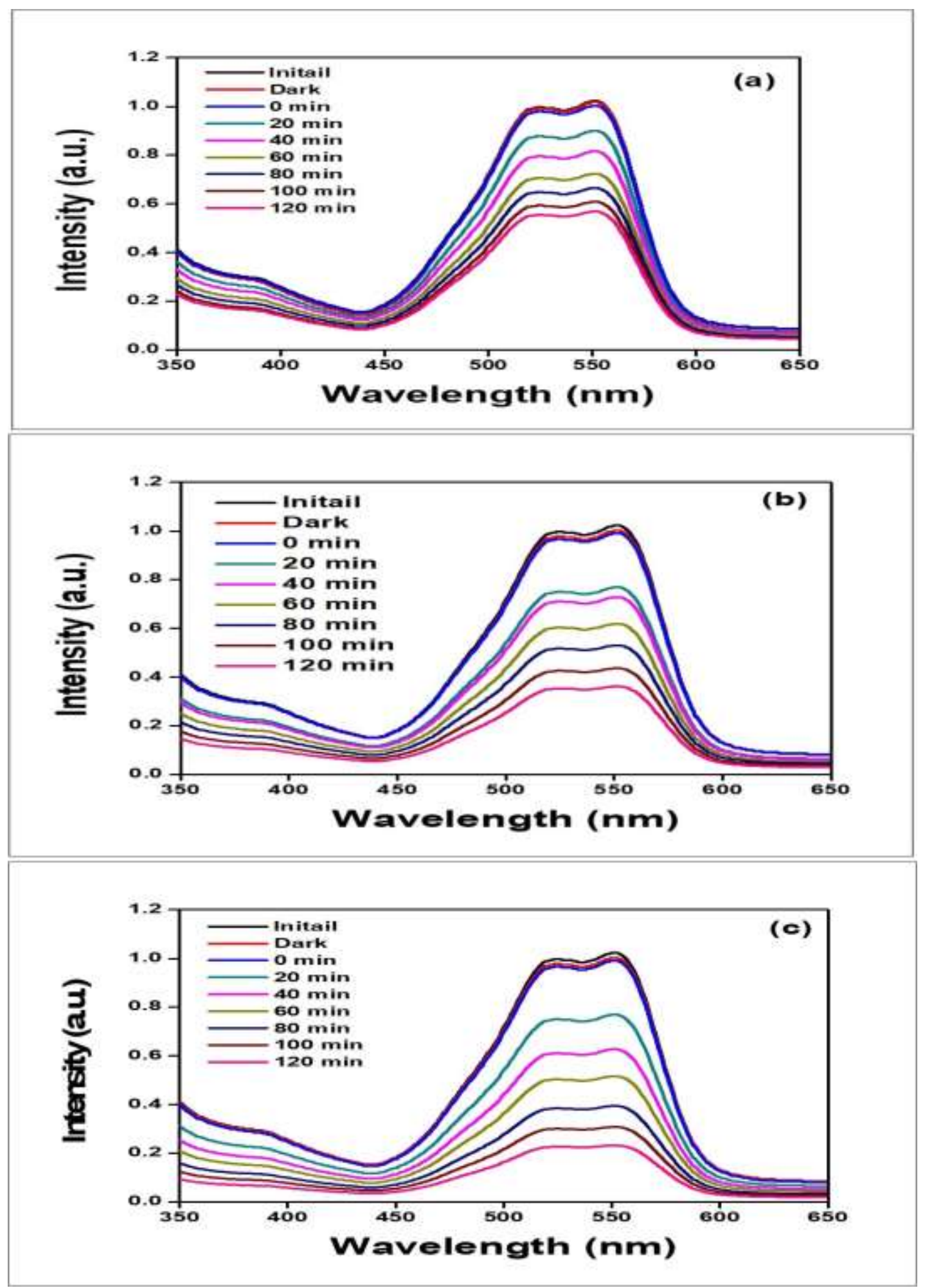

Fig. 10. Time dependent UV absorbance spectra of AR-13 dye with (a) PZ, (b) NZ, (c) NSZ photocatalysts. 


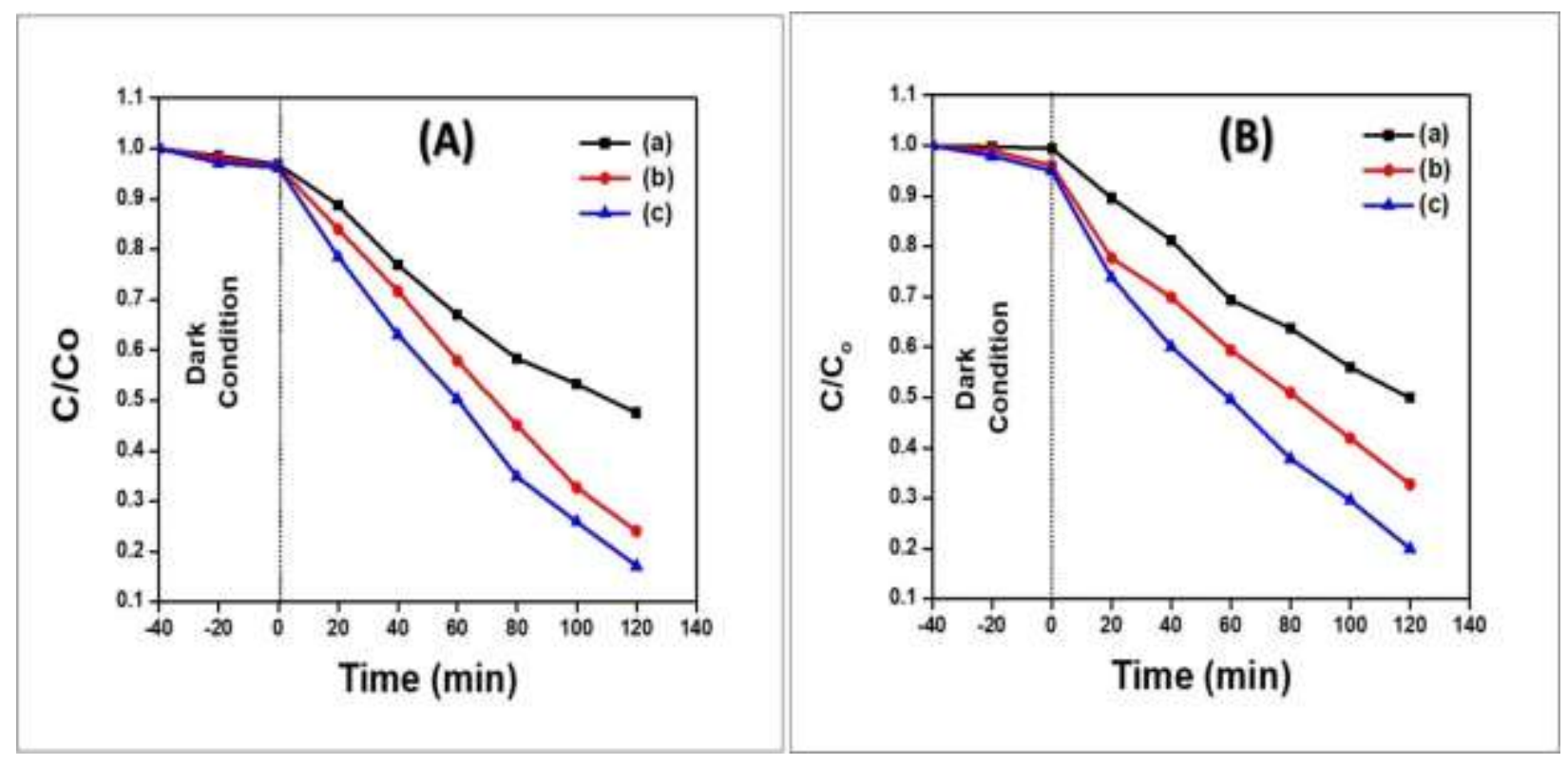

Fig.11 (A \& B). Variation of $\mathbf{C} / \mathbf{C}_{\mathbf{o}}$ with reactive time (T) of (a) PZ, (b) NZ and (c) NSZ NPs for AO-7 and AR-13 dyes.
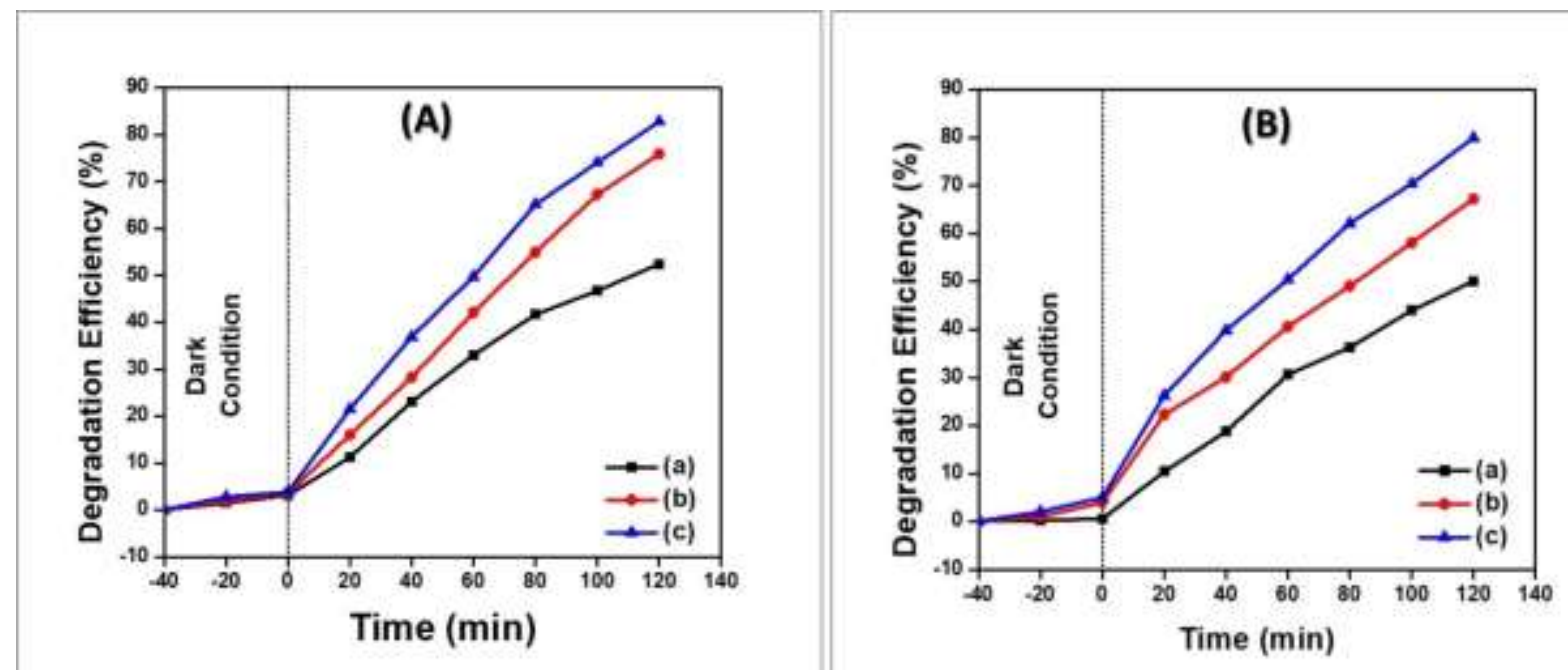

Fig. 12 (A \& B). Variation of degradation efficiency (\%) with reactive time (T) of (a) PZ, (b) NZ and (c) NSZ NPs for AO-7 and AR-13 dyes. 


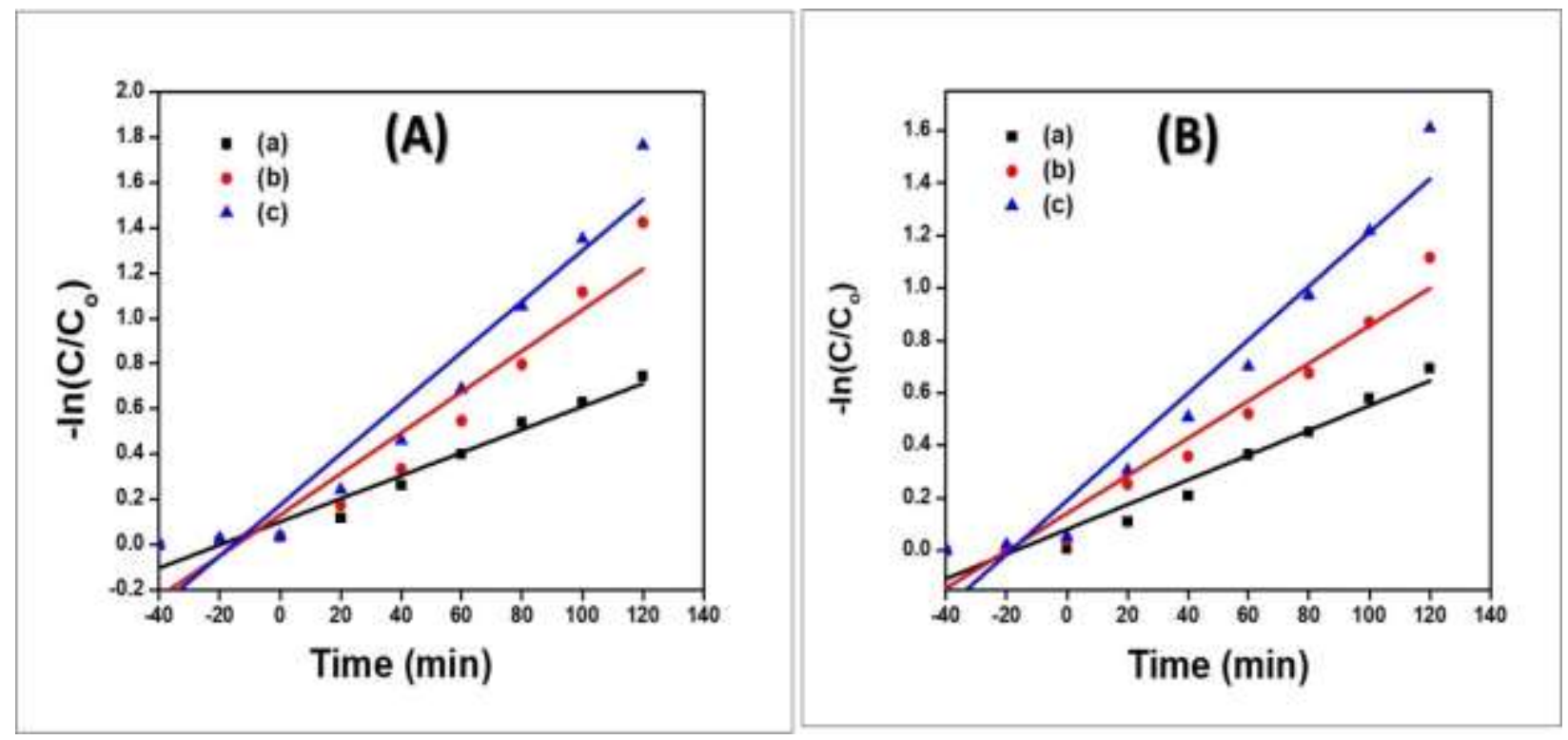

Fig. 13. Variation of $\ln \left(C_{t} / C_{0}\right)$ with reactive time $(T)$ of synthesized samples for (a) $R Y-86$ and (b) RR-2 dyes.

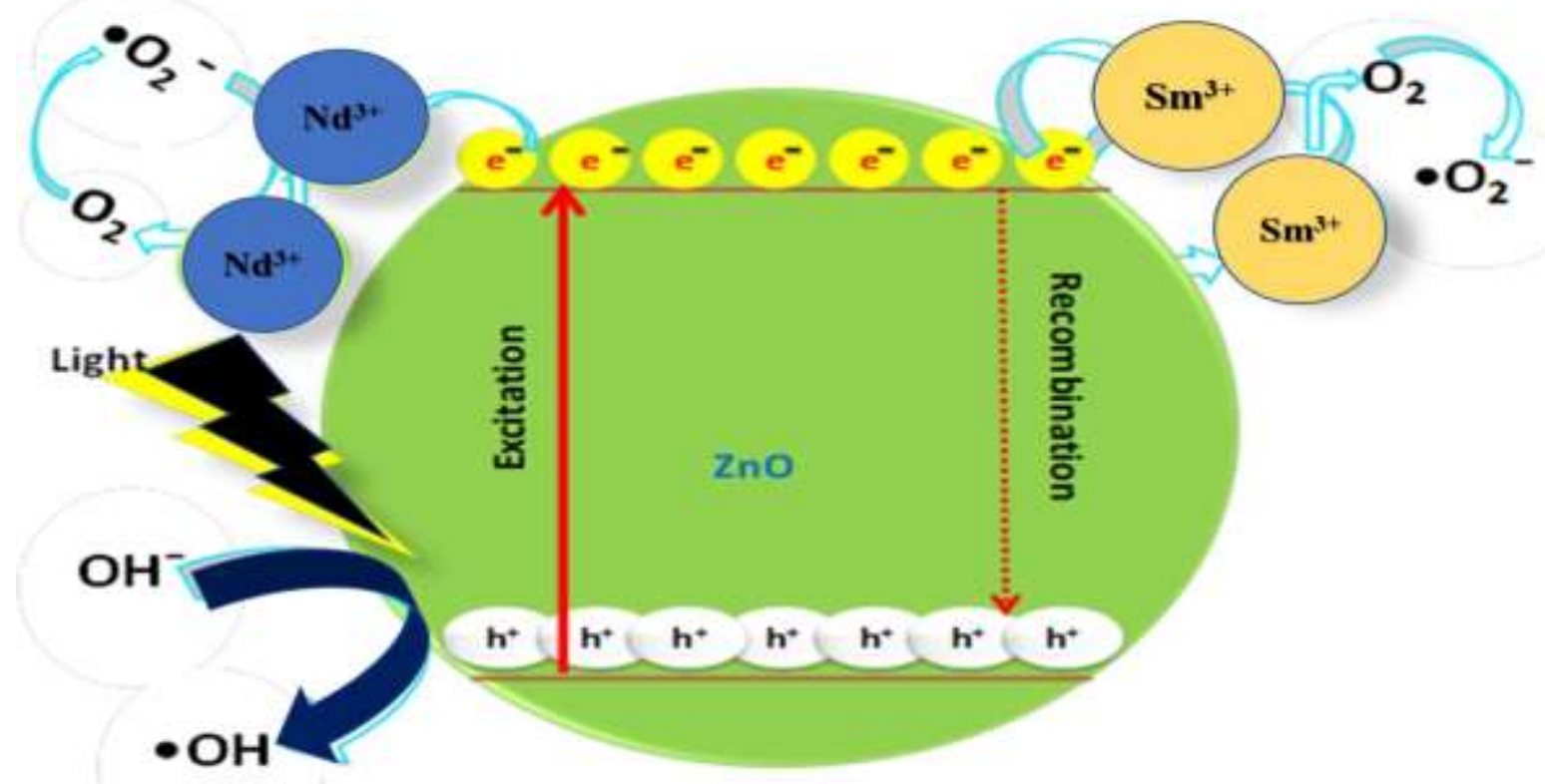

Figure 14. Schematic representation of photocatalytic degradation mechanism of NSZ NPs. 
Table 1: The cumulative photocatalytic result against AO-7 and AR-13 dyes for the prepared materials

\begin{tabular}{|c|c|c|c|c|}
\hline Synthetic Dyes & Materials & Rate constant $(\mathbf{k})\left(\mathbf{s}^{-\mathbf{1}}\right)$ & $\left(\mathbf{R}^{\mathbf{2}}\right)$ value & Degradation \% \\
\hline \multirow{3}{*}{ AO-7 } & PZ & 0.0051 & 0.9531 & 52 \\
\cline { 2 - 5 } & NZ & 0.0090 & 0.9242 & 75 \\
\cline { 2 - 5 } & NSZ & 0.0112 & 0.9169 & $\mathbf{8 2}$ \\
\hline \multirow{3}{*}{ AR-13 } & PZ & 0.0047 & 0.9615 & 50 \\
\cline { 2 - 5 } & NZ & 0.0071 & 0.9512 & 67 \\
\cline { 2 - 5 } & NSZ & 0.0102 & 0.9422 & $\mathbf{8 0}$ \\
\hline
\end{tabular}

